\title{
Update on liver disease management during the pandemic of coronavirus disease 2019 (COVID-19): 2021 KASL guideline
}

Ju-Yeon Cho', Young-Sun Lee ${ }^{2}$, Soon Sun Kim³ ${ }^{3}$ Do Seon Song ${ }^{4}$, Jeong-Hoon Lee ${ }^{5}$, and Ji Hoon Kim² on behalf of the Korean Association for the Study of the Liver

${ }^{1}$ Department of Internal Medicine, College of Medicine, Chosun University, Gwangju; ${ }^{2}$ Department of Internal Medicine, Guro Hospital, Korea University College of Medicine, Seoul; ${ }^{3}$ Department of Gastroenterology, Ajou University School of Medicine, Suwon; ${ }^{4}$ Department of Internal Medicine, St. Vincent's Hospital, The Catholic University of Korea, Seoul; ${ }^{5}$ Department of Internal Medicine and Liver Research Institute, Seoul National University College of Medicine, Seoul, Korea

Keywords: SARS-CoV-2; COVID-19; Hepatocellular carcinoma; Liver cirrhosis; Hepatitis

\section{INTRODUCTION}

This document has been accredited by the Korean Association for the Study of the Liver (KASL). This guideline is an update of the previous KASL guideline published in 2020. ${ }^{1}$ The update is based on recently accumulated data with particular focus on the treatment and vaccination section. The purpose of this guideline is to assist medical practitioners in the treatment of liver disease patients during the pandemic of coronavirus disease 2019 (COVID-19). The original guideline could be referred for an overall recommendation. As the knowledge regarding COVID-19 is continuously evolving, this document has not been thoroughly reviewed for its role as a medical standard of care or practice guideline. Liv- er disease management should be customized to accommodate specific medical situations and regional characteristics.

\section{DETAILS AND RECOMMENDATIONS}

\section{Severe acute respiratory syndrome coronavirus 2 (SARS-CoV-2) virus and the liver}

1) Cellular entry of SARS-CoV-2 is enabled by binding its spike protein to the angiotensin-converting enzyme 2 (ACE2) receptor and is primed by transmembrane protease serine subtype 2 (TMPRSS2). As a result, hepatocytes and bile duct epithelial

\footnotetext{
Abbreviations:

AASLD, American Association for the Study of Liver Diseases; ACE2, angiotensinconverting enzyme 2; ACEl, angiotensin converting enzyme inhibitor; ACTT, Adaptive COVID-19 Treatment Trial; ALT, alanine aminotransferase; ARB, angiotensin receptor inhibitor; Cl, confidence interval; COVID-19, coronavirus disease 2019; EASL, European Association for the Study of the Liver; FDA, Food and Drug Administration; FIB-4, Fibrosis 4; HCC, hepatocellular carcinoma; HIV, human immunodeficiency virus; HR, hazard ratio; IL-6, interleukin-6; KASL, Korean Association for the Study of the Liver; LFT, liver function test; $\mathrm{NIH}$, National Institutes of Health; RR, relative risk; SARS-CoV-2, severe acute respiratory syndrome coronavirus 2; TMPRSS2, transmembrane protease serine subtype 2
}

\section{Corresponding author : Ji Hoon Kim}

Department of Internal Medicine, Korea University Medical Center, 148 Gurodong-ro, Guro-gu, Seoul 08308, Korea

Tel: +82-2-2626-1038, Fax: +82-2-2626-1038 E-mail:kjhhepar@naver.com, kjhhepar@korea.ac.kr https://orcid.org/0000-0003-3924-0434 
cells with increased expression of ACE2 and TMPRSS2 become target cells for viral infection. ${ }^{2}$ SARS-CoV-2 has been detected in the hepatocyte cytoplasm with histological characteristic of viral infections. ${ }^{3}$

2) Abnormalities of liver function test (LFT)

a. Incidence rate: $14-83 \%^{4-7}$

b. Chronic liver disease can be affected by SARS-CoV-2 due to the primary toxicity of the virus to the liver, reactivation of antecedent chronic hepatitis virus, and damage caused by SARS-CoV-2 treatment.

Remdesivir and tocilizumab, treatments for COVID-19, may lead to liver injury; however, this potential side effect rarely results in the cessation of the drugs. ${ }^{6}$

c. Antithrombotic treatment in hospitalized COVID-19 patients may result in improved outcomes due to the increased risk of thromboembolic events in SARS-CoV-2 infection. ${ }^{8,9}$

d. In a multicenter retrospective cohort study analyzing 874 COVID-19 patients in Korea, 362 patients (41.4\%) showed abnormal LFT results. Among 130 patients with severe cases of COVID-19, 94 (72.3\%) had LFT abnormality. Patients with abnormal liver function showed longer hospitalization period and higher mortality rate. ${ }^{10}$

\section{[Recommendations]}

1. Hospitalized COVID-19 patients should be monitored for liver functions. LFT abnormality does not contraindicate the use of experimental or off-label treatments for COVID-19. Patients treated with remdesivir or tocilizumab should be monitored regularly irrespective of baseline LFTs.

\section{Management of outpatients with stable liver disease}

1) A large cohort study conducted in the UK (OpenSAFELY) confirmed increased COVID-19-related mortality rates in chronic liver disease patients (adjusted hazard ratio [HR], 1.75; 95\% confidence interval [CI], 1.51-2.03)."1

2) A cohort study including 2,780 COVID-19 patients reported significantly higher mortality rates in chronic liver disease patients (relative risk $[\mathrm{RR}], 2.8 ; 95 \% \mathrm{Cl}, 1.9-4.0$ ) and cirrhotic patients (RR, 4.6; $95 \% \mathrm{Cl}, 2.6-8.3$ ). ${ }^{12}$

3) Studies demonstrating the effectiveness of antiviral agents for hepatitis B or C (e.g., velpatasvir, ledipasvir, and tenofovir) against SARS-CoV-2 have been reported, but further evidence in clinical trials is needed. ${ }^{13}$
4) Based on a multicenter cohort observational study, alcoholic liver disease (HR, 2.42; 95\% Cl, 1.29-4.55), decompensated liver cirrhosis (HR, 2.91; 95\% Cl, 1.70-5.00) and hepatocellular carcinoma ( $\mathrm{HCC} ; \mathrm{HR}, 3.31 ; 95 \% \mathrm{Cl}, 1.53-7.16$ ) were independent risk factors for greater mortality in chronic liver disease patients with COVID-19. ${ }^{14}$ Nonalcoholic fatty liver, as well as chronic hepatitis $B$ and $C$ were not significant factors associated with the overall mortality rates of COVID-19 patients. ${ }^{14}$

5) A multinational registry of chronic liver disease patients including 70 autoimmune hepatitis patients reported that autoimmune hepatitis patients do not show a higher risk of severe SARS-CoV-2 infections, when compared to other causes of chronic liver disease patients. Also, the risk of being admitted to the intensive care unit and the average mortality rate of autoimmune hepatitis patients were not significantly higher compared to the patients without liver disease. Interestingly, the use of immunosuppressant was not related to mortality in patients with autoimmune hepatitis. ${ }^{15}$

\section{[Recommendations]}

1. Patients receiving antiviral therapy for hepatitis $B$ and $C$ infection should continue medication.

2. Initiation of treatment for hepatitis $B$ and $C$ in patients without COVID-19 should not be limited.

3. Initiation of hepatitis C treatment for COVID-19 patients is not routinely warranted and can be deferred to post-COVID-19 recovery.

\section{Management of patients with decompensated cirrhosis or waiting for a liver transplant}

1) High mortality rates were reported for COVID-19 patients with chronic liver disease. ${ }^{11,16}$

a. Two international reporting registries (COVID-Hep.net, COVIDCirrhosis.org) analyzed 152 chronic liver disease patients who tested positive for COVID-19 and discovered such patients to have a high mortality rate of $39.8 \%$. The mortality rate was greater with an increase in Child-Pugh scores. Progression to hepatic decompensation in COVID-19 patients also resulted in an elevated mortality rate. ${ }^{16}$

b. A multicenter study of hospitalized cirrhotic patients who tested positive for COVID-19 reported an increased mortality rate compared to COVID-19 patients without cirrhosis matched for age and sex. However, the difference in the 
mortality rate was not significant compared to cirrhotic patients without COVID-19."

c. In a retrospective cohort study that analyzed COVID-19 patients in Korea, patients with a higher Fibrosis 4 (FIB-4) score (FIB-4 >4.95) resulted in a significantly increased mortality rate in patients who received respiratory support (adjusted HR, 2.784; 95\% Cl, 1.691-4.585). ${ }^{18}$

d. In another Korean study analyzing 1,005 COVID-19 patients, patients with liver cirrhosis had worse outcomes and higher mortality (HR, 2.86; 95\% Cl, 1.04-9.30). However, there were no significant differences in respiratory symptoms and clinical outcomes between COVID-19 patients who had underlying liver disease and those who did not. ${ }^{19}$

2) A US nationwide study reported that the number of cirrhosis hospitalizations decreased during the COVID-19 pandemic. Model for end-stage liver disease score at admission was lower during the early stages of the pandemic than the later period. ${ }^{20}$ The hospital admission of cirrhotic patients may have been deferred by the pandemic due to the lack of medical resources. The indirect effects of COVID-19 regarding cirrhotic patients should be considered.

\section{Liver transplantation and post-transplantation care}

1) According to existing studies, the innate immune response to SARS-CoV-2 exacerbates pulmonary injury and immunosuppression might have a protective role. ${ }^{5,21,22}$

2) Based on the research to date, although there is a greater risk for COVID-19 infection in liver transplant patients, this is not associated with an increased risk of mortality.

a. A prospective study of liver transplant patients during the Spain pandemic (from February 28 to April 7, 2020) reported that 111 patients were diagnosed with COVID-19, which is double the number of COVID-19 diagnoses in the general population adjusted for age and sex (standardized incidence ratio, 191.2\%; 95\% Cl, 190.3-192.2\%). However, the mortality rate $(18 \%)$ of the liver transplant patients was significantly lower than that of the overall population (standardized mortality ratio, 95.5\%; 95\% Cl, 94.2-96.8\%). ${ }^{23}$

b. One hundred fifty-one liver transplant patients diagnosed with COVID-19 from two international registries (COVID-Hep registry and SECURE-Liver registry) were compared to COVID-19 patients without a history of liver transplantation using propensity score matching. Liver transplantation was not independently associated with an increase in mortality. ${ }^{24}$

\section{[Recommendations]}

1. Irrespective of the COVID-19 pandemic, liver transplantation should be conducted according to medical guidelines to minimize the risk of COVID-19 infection.

2. Minimizing the dose of immunosuppressants, especially anti-metabolites (azathioprine or mycophenolate), should be considered in liver transplant patients confirmed with COVID-19 infection. Individualized titration is necessary for immunosuppressants regarding both the severity of COVID-19 infection and the risk of rejection.

\section{Use of immunosuppressants in liver disease}

1) Recent studies have reported a decrease in overall mortality when administering steroids on severe cases of COVID-19. ${ }^{25}$

2) A case-control study including 10 autoimmune hepatitis patients confirmed for COVID-19 on immunosuppressants from Italy reported similar clinical outcomes compared to non-immunosuppressed patients with COVID-19. ${ }^{26}$

\section{[Recommendations]}

1. Minimizing the dose of immunosuppressants in patients who are taking immunosuppressants and confirmed for COVID-19 infection, especially anti-metabolites (azathioprine or mycophenolate), should be considered. Individualized titration is needed for immunosuppressants regarding both the severity of COVID-19 infection and the risk for aggravation of liver disease.

\section{Medication management and potential drug-drug interactions in COVID-19 patients}

1) Remdesivir is a US Food and Drug Administration (FDA)-approved drug for treating COVID-19.

a. Remdesivir is a nucleotide analogue with demonstrated activity against SARS-CoV-2 in human cell lines. ${ }^{27}$

b. Adaptive COVID-19 Treatment Trial (ACTT) reported a significant decrease in the recovery period of patients treated with remdesivir compared to the placebo group. Although not significant, the remdesivir group showed a slight improvement in survival rate compared to the placebo group. ${ }^{28,29}$

c. The US FDA approved the use of remdesivir in COVID-19 patients requiring hospitalization on October 22, 2020. The US 
National Institutes of Health $(\mathrm{NIH})$ recommends the use of remdesivir in patients with increased oxygen demand. . $^{30,31}$

d. Remdesivir is administered intravenously $200 \mathrm{mg}$ on day 1 of treatment, followed by a daily dose of $100 \mathrm{mg}$ for 5 days. ${ }^{30,31}$

e. As the final reports of ACTT said no benefit was observed in patients on mechanical ventilation or ECMO, these patients are excluded from remdesivir treatment in Korea. ${ }^{32}$

f. Adverse effects of remdesivir include nausea, vomiting, and increase in liver function. Regular follow-up of LFTs during treatment is recommended. ${ }^{30,33}$

g. There are currently no existing research on the pharmacological differences of remdesivir in patients with chronic liver disease, including cirrhosis. The US FDA recommends discontinuing remdesivir treatment in case of more than 10-fold increase of ALT or acute hepatitis accompanied by the elevation of ALT. ${ }^{30}$

2) Monoclonal antibodies targeting the SARS-CoV-2 spike protein, bamlanivimab alone or casirivimab+imdevimab, have been approved for emergency use authorization by the US FDA in mild to moderate COVID-19 patients with a high risk for progression to severe COVID-19. ${ }^{34}$

3) Dexamethasone is recommended in COVID-19 patients with increased oxygen demand, as decreased mortality rates were reported with its use.

a. The RECOVERY trial reported a significantly increased survival rate in patients receiving $6 \mathrm{mg}$ of dexamethasone daily by oral or intravenous methods for up to 10 days (RR, 0.83 ; 95\% Cl, 0.74-0.92; $P<0.001){ }^{25}$

4) Tocilizumab, an interleukin-6 (IL-6) inhibitor, did not improve the clinical course or survival rate in a double-blind, randomized controlled trial. ${ }^{35}$ Also, phase 3 COVACTA trial did not show significant improvement in the clinical course or the survival rates. ${ }^{36}$ However, studies with positive clinical results using IL-6 inhibitors have recently been reported. ${ }^{37}$

5) The use of lopinavir-ritonavir treatment in COVID-19 patients showed no benefit compared to standard care, and the treatment was halted prematurely in 13 patients (13.8\%) due to adverse events. ${ }^{38}$

a. The US NIH currently does not recommend lopinavir/ritonavir or human immunodeficiency virus (HIV) protease inhibitors as COVID-19 treatments. ${ }^{38}$

6) Although SARS-CoV-2 inhibition with hydroxychloroquine has been demonstrated in vitro, ${ }^{39}$ ineffective or harmful results in the clinical studies have led to NIH recommendations against its use. ${ }^{38}$

7) The US FDA has issued an emergency use authorization to al- low convalescent plasma transfusion for severe COVID-19 treatment based on reports of potential benefit with its use. .0,41 $^{-1}$

8) Angiotensin converting enzyme inhibitors (ACEIs) and angiotensin receptor inhibitors (ARBS) promote SARS-CoV-2 infection as they increase ACE2 expression, the target for the virus to enter cells. ${ }^{42}$ Nevertheless, existing studies have reported that ACEI/ARB have cardio-pulmonary protective effects, and increased ACE2 expression can reduce acute lung injury. Therefore, there is not enough evidence to limit ACEI/ARB treatment in COVID-19 patients. ${ }^{43,44}$

\section{[Recommendations]}

1. Remdesivir is administered intravenously $200 \mathrm{mg}$ on the first day of treatment, followed by a daily dose of $100 \mathrm{mg}$ for 5 days in patients with increased oxygen demand.

2. Remdesivir treatment should be halted if more than a 10fold increase of alanine aminotransferase (ALT) is present or if liver inflammation is present with the elevation of ALT.

3. Dexamethasone $6 \mathrm{mg}$ daily by oral or intravenous methods for up to 10 days is recommended in severe COVID-19 patients with increased oxygen demand or those on mechanical ventilation.

4. Recommendations against the use of lopinavir/ritonavir or HIV protease inhibitors as COVID-19 treatments are ensued based on current research.

5. Hydroxychloroquine treatment with or without azithromycin may bring about serious side effects; therefore, its use is not recommended.

6. Treatment with tocilizumab, an IL-6 inhibitor, warrants caution as controversial studies are being reported.

7. Patients with ACEI/ARB medication are recommended to continue treatment.

\section{COVID-19 vaccination strategies in chronic liver disease patients}

1) SARS-CoV-2 enters the host cell by attaching its spike protein to the ACE2 receptor. Hence, vaccine research and development have been focused on inducing an immune response against the viral spike protein of SARS-CoV-2.

2) Several vaccines differing in the target and delivery methods have been successfully developed, of which mRNA vaccine and virus-vector vaccine are the most prominent. Currently, four COVID-19 vaccines have been approved by the Korean Ministry 
of Food and Drug Safety; AstraZeneca, Johnson \& Johnson/ Janssen, Pfizer, and Moderna COVID-19 vaccines. ${ }^{45}$ All of these vaccines have been approved by both the US FDA and the European Medicines Agency, except for the AstraZeneca COVID-19 vaccine, which is yet to be approved for use by the US FDA.

3) The AstraZeneca COVID-19 vaccine uses a modified version of a chimpanzee adenovirus (ChAdOx1) containing the full-length, codon-optimized gene encoding the spike protein of the SARS$\mathrm{CoV}-2$. After the vaccination, the assembled surface antigen of the spike protein induces an immune response against the SARS-CoV-2 to develop protective neutralizing antibodies.

a. Phase 3 clinical trials of the AstraZeneca COVID-19 vaccine resulting in an average vaccine efficacy of $70.4 \%$ without a serious safety event led to its approval for emergency use in the UK. ${ }^{46}$

b. A large phase 3 trial of the AstraZeneca COVID-19 vaccine in the United States reported a vaccine efficacy of $79 \%$ in decreasing the symptoms of COVID-19 which increased to $100 \%$ in preventing severe COVID-19. In people over the age of 65 years, the protective effect was reported as $80 \% .{ }^{47}$

c. Phase 3 trials of the AstraZeneca COVID-19 vaccine excluded chronic liver disease patients and alcoholics. ${ }^{48}$

4) Johnson \& Johnson/Janssen COVID-19 vaccine uses the adenovirus 26 vector to deliver the genes necessary for assembling the SARS-CoV-2 spike protein. Unlike other vaccines developed, only one dose of vaccination is required with the Johnson \& Johnson/Janssen COVID-19 vaccine.

a. A phase 3 trial of the Johnson \& Johnson/Janssen COVID-19 vaccine, including about 40,000 participants, reported a vaccine efficacy of $66.9 \%$ on day 14 and $66.1 \%$ on day 28 . The vaccine efficacy for preventing the development of severe COVID-19 was $76.7 \%$ on day 14 and $85.4 \%$ on day $28 .{ }^{49}$

b. The proportion of chronic liver disease patients included in the trial was $0.5 \%(207$ of 43,783$))^{49}$

5) Pfizer and Moderna COVID-19 vaccines are based on the SARSCoV-2 spike protein encoded by mRNA in lipid nanoparticles. The assembly of a stabilized spike protein antigen in its pre-fusion form induces an immune response in vivo.

a. The Pfizer COVID-19 vaccine proved a vaccine efficacy of $95 \%$ without safety concerns in phase 3 clinical trials. The proportion of chronic liver disease patients included in the trial was $0.6 \%$ (217 of 37,706$){ }^{48}$

b. The Moderna COVID-19 vaccine proved a vaccine efficacy of $94.1 \%$ without safety concerns in phase 3 clinical trials. The proportion of chronic liver disease patients included in the trial was $0.6 \%$ (196 of 30,357).

6) Thrombotic events, including cerebral venous sinus thrombosis, have been reported with the administration of the AstraZeneca COVID-19 vaccine and Johnson \& Johnson/Janssen COVID-19 vaccine. $^{50,51}$

a. Although the exact pathogenesis has not been confirmed, the leakage of DNA from the adenovirus infected cells binding to platelet factor 4 seem to trigger the production of auto-antibodies. ${ }^{50,52,53}$

b. The incidence of thrombotic events developed 5 to 24 days after the first vaccination of the AstraZeneca COVID-19 vaccine. The risk for developing severe adverse events was greater in the age group of 20-29 years (1.1 cases per 100,000 persons) compared to the age group of $60-69$ years ( 0.2 cases per 100,000 persons). ${ }^{52,54}$ The analysis of 281,264 AstraZeneca COVID-19 vaccinees in Denmark and Norway reported 59 cases of venous thromboembolism, which was 11 cases greater than the expected 30 cases per 100,000 persons. ${ }^{55}$ With the Johnson \& Johnson/Janssen COVID-19 vaccine, thrombotic events developed 6 to 13 days after the first vaccination, and the incidence was predominant in those between the ages of 18 and 48 years. ${ }^{50}$

c. Public Health England recommends seeking medical advice if the following symptoms develop after vaccination. ${ }^{56}$

- A new, severe headache which is not relieved by painkillers or gets worse

- A headache which worsens when lying down or bending over

- Headache accompanied by blurred vision, nausea and vomiting, aphasia, weakness, drowsiness, or seizure

- Development of petechiae or bleeding

- Shortness of breath, chest pain, edema of the lower extremities, or persistent abdominal pain

d. Although there is a risk of thrombotic events with COVID-19 vaccines, the greater benefits of vaccination has led to the recommendations of active vaccination. However, additional risk and benefit analyses of the AstraZeneca and Johnson \& Johnson/Janssen COVID-19 vaccines must be conducted in people under the age of 30 years.

7) The impaired innate and acquired immunity of severe liver disease patients results in decreased response to any vaccination. ${ }^{57}$ Studies have reported increased vaccine efficacy when doubling the dose of hepatitis B vaccination in cirrhotic patients. No research has been conducted regarding the administration of an 
increased dose of the COVID-19 vaccine, and doubling the dose or frequency is not recommended in cirrhotic patients. ${ }^{58,59}$

8) The safety and efficacy of the COVID-19 vaccine in chronic liver disease patients have not been fully elucidated. However, the European Association for the Study of the Liver (EASL) recommends vaccination early as possible in chronic liver disease patients, as there is a greater risk of severe COVID-19. ${ }^{60}$ The American Association for the Study of Liver Diseases (AASLD) recommends the administration of mRNA vaccines in chronic liver disease patients. ${ }^{61}$ Additional research should be conducted regarding the safety and vaccine efficacy of vaccines in chronic liver diseases, including decompensated liver cirrhosis, and the risk and benefit of vaccination must be further evaluated.

9) Research regarding the superiority of adenovirus-vector vaccine or mRNA-based vaccine in chronic liver disease patients has yet to be conducted. Clinical trials of the COVID-19 vaccines included only a small proportion of chronic liver disease patients $(0.5-0.6 \%)$, and sub-group analyses have not been reported. ${ }^{48,49,62}$ Although studies have found that adenovirus-vector vaccines in chronic hepatitis $C$ patients are safe, there are concerns regarding the use of adenovirus-vector vaccines in immune-compromised patients, including chronic liver disease patients, and further research is required. ${ }^{63,64}$

10) Data regarding the safety and effectiveness of the COVID-19 vaccines in liver transplant patients is limited. Although it is not recommended to vaccinate transplant patients with live vaccines, as the adenovirus-vector or the mRNA vaccines cannot replicate, the EASL, the AASLD, and the Korean Society for Transplantation recommend the administration of COVID-19 vaccines in this population. ${ }^{60,65,66}$ The AASLD recommends vaccination at least 3 months after transplantation when immunosuppression is lower and the patient is stable. However, vaccination can be undertaken as early as 6 weeks post-transplant if there is a greater risk for other comorbidities during a pandemic.

11) Continuous research regarding the safety and efficacy of the COVID-19 vaccine should be conducted in patients with chronic liver disease.

\section{[Recommendations]}

1. COVID-19 vaccination should be prioritized for chronic liver disease and liver transplant patients. The patients should be monitored for any development of adverse events.
2. Chronic hepatitis B and C patients should not withhold their medications while receiving COVID-19 vaccines. Treatment for HCC should be continued during the COVID-19 vaccinations.

3. Although COVID-19 vaccines pose the risk of thrombotic events, the greater benefits of vaccination have led to the recommendations for active vaccination.

4. Patients with a history of recent infection or symptoms, such as fever, should be vaccinated after achieving medical stability.

5. All chronic liver disease and liver transplant patients, including vaccinated recipients, should continue to adhere to infection prevention and control guidelines and also practice social distancing.

\section{Authors' contribution}

Manuscript preparation and article reviews: Cho JY, Lee YS, Kim SS, Song DS, Lee JH, Kim JH. All authors revised and approved the final version of the manuscript.

\section{Conflicts of Interest}

The authors have no conflicts to disclose.

\section{REFERENCES}

1. Cho JY, Kim SS, Lee YS, Song DS, Lee JH, Kim JH. Management of liver diseases during the pandemic of coronavirus disease-19. Clin Mol Hepatol 2020;26:243-250.

2. Hoffmann $M$, Kleine-Weber $H$, Schroeder $S$, Krüger $N$, Herrler $T$, Erichsen $\mathrm{S}$, et al. SARS-CoV-2 cell entry depends on ACE2 and TMPRSS2 and is blocked by a clinically proven protease inhibitor. Cell 2020;181:271-280.e8.

3. Wang Y, Liu S, Liu H, Li W, Lin F, Jiang L, et al. SARS-CoV-2 infection of the liver directly contributes to hepatic impairment in patients with COVID-19. J Hepatol 2020;73:807-816.

4. Chen N, Zhou M, Dong X, Qu J, Gong F, Han Y, et al. Epidemiological and clinical characteristics of 99 cases of 2019 novel coronavirus pneumonia in Wuhan, China: a descriptive study. Lancet 2020;395:507-513

5. Huang C, Wang Y, Li X, Ren L, Zhao J, Hu Y, et al. Clinical features of patients infected with 2019 novel coronavirus in Wuhan, China. Lancet 2020;395:497-506.

6. Zhang C, Shi L, Wang FS. Liver injury in COVID-19: management and challenges. Lancet Gastroenterol Hepatol 2020;5:428-430.

7. Xu L, Liu J, Lu M, Yang D, Zheng X. Liver injury during highly patho- 
genic human coronavirus infections. Liver Int 2020;40:998-1004.

8. Bikdeli B, Madhavan MV, Jimenez D, Chuich T, Dreyfus I, Driggin E, et al. COVID-19 and thrombotic or thromboembolic disease: implications for prevention, antithrombotic therapy, and follow-up: JACC state-of-the-art review. J Am Coll Cardiol 2020;75:2950-2973.

9. Paranjpe I, Fuster V, Lala A, Russak AJ, Glicksberg BS, Levin MA, et al. Association of treatment dose anticoagulation with in-hospital survival among hospitalized patients with COVID-19. J Am Coll Cardiol 2020;76:122-124.

10. Song JE, Kang MK, Lee YR, Lee CH, Park JG, Kweon YO, et al. Multicenter analysis of clinical features and prognosis of COVID-19 patients with hepatic impairment. Gut Liver 2021;15:606-615.

11. Williamson EJ, Walker AJ, Bhaskaran K, Bacon S, Bates C, Morton $C E$, et al. Factors associated with COVID-19-related death using OpenSAFELY. Nature 2020;584:430-436.

12. Singh S, Khan A. Clinical characteristics and outcomes of coronavirus disease 2019 among patients with preexisting liver disease in the United States: a multicenter research network study. Gastroenterology 2020;159:768-771.e3.

13. Lens S, Miquel M, Mateos-Muñoz B, García-Samaniego J, Forns $X$. SARS-CoV-2 in patients on antiviral HBV and HCV therapy in Spain. J Hepatol 2020;73:1262-1263.

14. Kim D, Adeniji N, Latt N, Kumar S, Bloom PP, Aby ES, et al. Predictors of outcomes of COVID-19 in patients with chronic liver disease: US multi-center study. Clin Gastroenterol Hepatol 2021;19:14691479.e19.

15. Marjot T, Buescher G, Sebode M, Barnes E, Barritt AS 4th, Armstrong MJ, et al. SARS-CoV-2 infection in patients with autoimmune hepatitis. J Hepatol 2021;74:1335-1343.

16. Moon AM, Webb GJ, Aloman C, Armstrong MJ, Cargill T, Dhanasekaran $\mathrm{R}$, et al. High mortality rates for SARS-CoV-2 infection in patients with pre-existing chronic liver disease and cirrhosis: preliminary results from an international registry. J Hepatol 2020;73:705708.

17. Bajaj JS, Garcia-Tsao G, Biggins SW, Kamath PS, Wong F, McGeorge $\mathrm{S}$, et al. Comparison of mortality risk in patients with cirrhosis and COVID-19 compared with patients with cirrhosis alone and COVID-19 alone: multicentre matched cohort. Gut 2021;70:531-536.

18. Park JG, Kang MK, Lee YR, Song JE, Kim NY, Kweon YO, et al. Fibrosis-4 index as a predictor for mortality in hospitalised patients with COVID-19: a retrospective multicentre cohort study. BMJ Open 2020;10:e041989.

19. Lee YR, Kang MK, Song JE, Kim HJ, Kweon YO, Tak WY, et al. Clinical outcomes of coronavirus disease 2019 in patients with preexisting liver diseases: a multicenter study in South Korea. Clin Mol Hepatol 2020;26:562-576.

20. Mahmud N, Hubbard RA, Kaplan DE, Serper M. Declining cirrhosis hospitalizations in the wake of the COVID-19 pandemic: a national cohort study. Gastroenterology 2020;159:1134-1136.e3.

21. D'Antiga L. Coronaviruses and immunosuppressed patients: the facts during the third epidemic. Liver Transpl 2020;26:832-834.

22. Mehta P, McAuley DF, Brown M, Sanchez E, Tattersall RS, Manson JJ, et al. COVID-19: consider cytokine storm syndromes and immunosuppression. Lancet 2020;395:1033-1034.

23. Colmenero J, Rodríguez-Perálvarez $M$, Salcedo $M$, Arias-Milla $A$, Muñoz-Serrano A, Graus J, et al. Epidemiological pattern, incidence, and outcomes of COVID-19 in liver transplant patients. J Hepatol 2021;74:148-155.

24. Webb GJ, Marjot T, Cook JA, Aloman C, Armstrong MJ, Brenner EJ, et al. Outcomes following SARS-CoV-2 infection in liver transplant recipients: an international registry study. Lancet Gastroenterol Hepatol 2020;5:1008-1016.

25. RECOVERY Collaborative Group, Horby P, Lim WS, Emberson JR, Mafham M, Bell JL, et al. Dexamethasone in hospitalized patients with Covid-19. N Engl J Med 2021;384:693-704.

26. Gerussi A, Rigamonti C, Elia C, Cazzagon N, Floreani A, Pozzi R, et al. Coronavirus disease 2019 (COVID-19) in autoimmune hepatitis: a lesson from immunosuppressed patients. Hepatol Commun 2020;4:1257-1262.

27. Wang M, Cao R, Zhang L, Yang X, Liu J, Xu M, et al. Remdesivir and chloroquine effectively inhibit the recently emerged novel coronavirus (2019-nCoV) in vitro. Cell Res 2020;30:269-271.

28. Goldman JD, Lye DCB, Hui DS, Marks KM, Bruno R, Montejano R, et al. Remdesivir for 5 or 10 days in patients with severe Covid-19. N Engl J Med 2020;383:1827-1837.

29. Beigel JH, Tomashek KM, Dodd LE, Mehta AK, Zingman BS, Kalil AC, et al. Remdesivir for the treatment of Covid-19 - final report. N Engl J Med 2020;383:1813-1826.

30. Sarges P, Steinberg JM, Lewis JH. Drug-induced liver injury: highlights from a review of the 2015 literature. Drug Saf 2016;39:801821.

31. Kullak-Ublick GA, Andrade RJ, Merz M, End P, Benesic A, Gerbes $A L$, et al. Drug-induced liver injury: recent advances in diagnosis and risk assessment. Gut 2017;66:1154-1164.

32. National Medical Center. Administration and management of Veklury (remdesivir) for medical facilities (ver. 07). National Medical Center web site, <https://www.nmc.or.kr/mdntf/bbs/B0000062/ view.do?nttld=10845\&menuNo=50000 >. Accessed 16 Sep 2021.

33. Montastruc F, Thuriot S, Durrieu G. Hepatic disorders with the use of remdesivir for coronavirus 2019. Clin Gastroenterol Hepatol 2020;18:2835-2836.

34. Saviano A, Wrensch F, Ghany MG, Baumert TF. Liver disease and coronavirus disease 2019: from pathogenesis to clinical care. Hepatology 2021;74:1088-1100.

35. Stone JH, Frigault MJ, Serling-Boyd NJ, Fernandes AD, Harvey L, Foulkes AS, et al. Efficacy of tocilizumab in patients hospitalized 
with Covid-19. N Engl J Med 2020;383:2333-2344.

36. Björnsson ES. Hepatotoxicity by drugs: the most common implicated agents. Int J Mol Sci 2016;17:224.

37. REMAP-CAP Investigators, Gordon AC, Mouncey PR, Al-Beidh F, Rowan $\mathrm{KM}$, Nichol $A D$, et al. Interleukin-6 receptor antagonists in critically III patients with Covid-19. N Engl J Med 2021;384:1491-1502.

38. Cao B, Wang Y, Wen D, Liu W, Wang J, Fan G, et al. A trial of lopinavir-ritonavir in adults hospitalized with severe Covid-19. N Engl J Med 2020;382:1787-1799.

39. Yao X, Ye F, Zhang M, Cui C, Huang B, Niu P, et al. In vitro antiviral activity and projection of optimized dosing design of hydroxychloroquine for the treatment of severe acute respiratory syndrome coronavirus 2 (SARS-CoV-2). Clin Infect Dis 2020;71:732-739.

40. Joyner MJ, Bruno KA, Klassen SA, Kunze KL, Johnson PW, Lesser $E R$, et al. Safety update: COVID-19 convalescent plasma in 20,000 hospitalized patients. Mayo Clin Proc 2020;95:1888-1897.

41. Shen C, Wang Z, Zhao F, Yang Y, Li J, Yuan J, et al. Treatment of 5 critically III patients with COVID-19 with convalescent plasma. JAMA 2020;323:1582-1589.

42. Fang $L$, Karakiulakis $G$, Roth $M$. Are patients with hypertension and diabetes mellitus at increased risk for COVID-19 infection? Lancet Respir Med 2020;8:e21.

43. Vaduganathan $M$, Vardeny $O$, Michel T, McMurray JJV, Pfeffer MA, Solomon SD. Renin-angiotensin-aldosterone system inhibitors in patients with Covid-19. N Engl J Med 2020;382:1653-1659.

44. Guo J, Huang Z, Lin L, Lv J. Coronavirus disease 2019 (COVID-19) and cardiovascular disease: a viewpoint on the potential influence of angiotensin-converting enzyme inhibitors/angiotensin receptor blockers on onset and severity of severe acute respiratory syndrome coronavirus 2 infection. J Am Heart Assoc 2020;9:e016219.

45. COVID-19 Vaccination Reponse Promotion. COVID-19 vaccination guideline (helathcare personnel). COVID-19 Vaccination Reponse Promotion web site, <https://ncv.kdca.go.kr/boardDownload.es? bid=0035\&list_no=299\&seq=1>. Accessed 16 Sep 2021 .

46. Voysey M, Clemens SAC, Madhi SA, Weckx LY, Folegatti PM, Aley PK, et al. Safety and efficacy of the ChAdOx $1 \mathrm{nCoV}-19$ vaccine (AZD1222) against SARS-CoV-2: an interim analysis of four randomised controlled trials in Brazil, South Africa, and the UK. Lancet 2021;397:99-111.

47. ClinicalTrials.gov. Phase III double-blind, placebo-controlled study of AZD1222 for the prevention of COVID-19 in adults. ClinicalTrials.gov web site, <https://clinicaltrials.gov/ct2/show/NCT04516746?term= NCT04516746\&draw=2\&rank=1>. Aaccessed 16 Sep 2021

48. Marjot $T$, Webb GJ, Barritt AS, Ginès $P$, Lohse AW, Moon AM, et al. SARS-CoV-2 vaccination in patients with liver disease: responding to the next big question. Lancet Gastroenterol Hepatol 2021;6:156158.

49. U.S. Food \& Drug Administration (FDA). Janssen. FDA Briefing Docu- ment: Johnson \&Johnson/Janssen COVID-19 Vaccine. Vaccines and Related Biological Products Advisory Committee Meeting. FDA web site, <https://www.fda.gov/media/146217/download>. Accessed 16 Sep 2021.

50. Centers for Disease Control and Prevention (CDC). Reports of cerebral venous sinus thrombosis with thrombocytopenia after Janssen COVID-19 vaccine. CDC web site, <https://www.cdc.gov/vaccines/ acip/meetings/downloads/slides-2021-04/03-COVID-Shimabukuro-508.pdf>. Accessed 16 Sep 2021.

51. ITV. AstraZeneca vaccine: timeline of what's happened since European countries suspended use of Covid jab. ITV web sit, <https:// www.itv.com/news/2021-04-07/astrazeneca-vaccine-timeline-ofwhats-happened-since-european-countries-suspended-use-ofcovid-jab>. Accessed 16 Sep 2021.

52. Furie KL, Cushman M, Elkind MSV, Lyden PD, Saposnik G; American Heart Association/American Stroke Association Stroke Council Leadership. Diagnosis and management of cerebral venous sinus thrombosis with vaccine-induced immune thrombotic thrombocytopenia. Stroke 2021;52:2478-2482.

53. Greinacher A, Thiele T, Warkentin TE, Weisser K, Kyrle PA, Eichinger S. Thrombotic thrombocytopenia after ChAdOX1 nCov-19 vaccination. N Engl J Med 2021;384:2092-2101.

54. Hunter PR. Thrombosis after covid-19 vaccination. BMJ 2021;373:n958.

55. Notarnicola A, Barsotti S, Näsman L, Tang Q, Holmqvist M, Lundberg IE, et al. Evaluation of risk factors and biomarkers related to arterial and venous thrombotic events in idiopathic inflammatory myopathies. Scand J Rheumatol 2021;52:390-397.

56. GOV.UK. Guidance: covid-19 vaccination and blood clotting. GOV. UK web site, <https://www.gov.uk/government/publications/covid19-vaccination-and-blood-clotting/covid-19-vaccination-and-bloodclotting >. Accessed 16 Sep 2021.

57. Bonnel AR, Bunchorntavakul C, Reddy KR. Immune dysfunction and infections in patients with cirrhosis. Clin Gastroenterol Hepatol 2011;9:727-738.

58. Bonazzi PR, Bacchella T, Freitas AC, Osaki KT, Lopes MH, Freire MP, et al. Double-dose hepatitis $B$ vaccination in cirrhotic patients on a liver transplant waiting list. Braz J Infect Dis 2008;12:306-309.

59. Pascasio JM, Aoufi S, Gash A, Sousa JM, Perea R, Sayago M, et al. Response to a vaccination schedule with 4 doses of 40 microg against hepatitis $B$ virus in cirrhotic patients evaluated for liver transplantation. Transplant Proc 2008;40:2943-2945.

60. Cornberg M, Buti M, Eberhardt CS, Grossi PA, Shouval D. EASL position paper on the use of COVID-19 vaccines in patients with chronic liver diseases, hepatobiliary cancer and liver transplant recipients. J Hepatol 2021;74:944-951.

61. Fix OK, Hameed B, Fontana RJ, Kwok RM, McGuire BM, Mulligan $D C$, et al. Clinical best practice advice for hepatology and liver transplant providers during the COVID-19 pandemic: AASLD expert 
panel consensus statement. Hepatology 2020;72:287-304.

62. Baden LR, El Sahly HM, Essink B, Kotloff K, Frey S, Novak R, et al. Efficacy and safety of the mRNA-1273 SARS-CoV-2 vaccine. N Engl J Med 2021;384:403-416.

63. Swadling L, Halliday J, Kelly C, Brown A, Capone S, Ansari MA, et al. Highly-immunogenic virally-vectored T-cell vaccines cannot overcome subversion of the T-cell response by HCV during chronic infection. Vaccines (Basel) 2016;4:27.

64. Kelly C, Swadling L, Capone S, Brown A, Richardson R, Halliday J, et al. Chronic hepatitis $C$ viral infection subverts vaccine-induced T-cell immunity in humans. Hepatology 2016;63:1455-1470.

65. The Korean Society for Transplantation (KST). Recommendation on COVID-19 vaccination in transplant patients. KST web site, <https:// www.mykst.org/content/community/post_view.php?bt=6\&post_ $\mathrm{id}=728$ \&page $=1>$. Accessed 16 Sep 2021.

66. Fix OK, Blumberg EA, Chang KM, Chu J, Chung RT, Goacher EK, et al. American Association for the Study of Liver Diseases expert panel consensus statement: vaccines to prevent coronavirus disease 2019 infection in patients with liver disease. Hepatology 2021;74:10491064. 